\title{
Suitable model for thin-layer drying of root vegetables and onion
}

\author{
Krzysztof Górnicki@*, Agnieszka Kaleta®, and Aneta Choińska \\ Institute of Mechanical Engineering, Warsaw University of Life Sciences - SGGW, Nowoursynowska 164, 02-787 Warsaw, Poland
}

Received February 22, 2019; accepted December 10, 2019

\begin{abstract}
The drying behaviour of carrot, parsley, red beetroot and onion slices of 5 and $10 \mathrm{~mm}$ thickness was investigated in a convective dryer at a drying temperature of 50,60 and $70^{\circ} \mathrm{C}$ under natural convection conditions. The experimental drying data of the vegetables slices obtained were fitted to five empirical thin-layer models: Lewis (Newton), Henderson and Pabis, Page, Modified Page, Wang and Singh. The effects of the vegetable species, air drying temperature, and slice thickness on the model parameters were determined. Four statistical tools, namely, the determination coefficient, root mean square error, reduced chi-square, and $t$-statistic method were applied to determine the fittings. The Page model with the model parameters determined by a summation equation, a square type dependence for the drying air temperature and a rational one for the slice thickness is recommended as the most suitable model $\left(\mathrm{R}^{2}=0.9699, R M S E=0.0587\right.$, $\chi^{2}=0.0035, t$-stat $=0.6739$ ).

Keywords: root vegetables, onion, drying kinetics, modelling, drying models
\end{abstract}

\section{INTRODUCTION}

Drying is one of the oldest and most common operations in the food industry. Food products are usually dried to maintain food safety because the process reduces both enzymatic and microbial changes during the storage period and thereby improves the shelf life of the product (Younis et al., 2018). Large quantities of fruits, vegetables and other plant tissues are also dried to reduce their weights and packaging costs, enhance appearance, and maintain flavour and nutritional values. Although the enhancement of product quality, economic considerations, and environmental concerns are the main aims of the drying process, the most important objective is preservation which depends on the drying mechanisms (Barba et al., 2014).

*Corresponding author e-mail: krzysztof_gornicki@sggw.pl
The process of drying moist food involves a combination of heat and mass transfer. Therefore, the drying process could be described as moisture removal by means of simultaneous heat and mass transfer between the product and the surrounding air. The moisture is removed mainly by vaporization which occurs for the most part due to temperature and air convection forces (Avhad and Marchetti, 2016).

Studying the drying kinetics may be of particular relevance in choosing the optimal conditions for a satisfactory drying process (Opalić et al., 2009). Full-scale experimentation with different bioproducts and system configurations is in the main costly and therefore impractical. Hence, the mathematical modelling of the drying processes and equipment is a very important issue for drying technology. The development of a mathematical model for the drying process allows for the selection of the most adequate operating conditions and hence the most appropriate size of the drying equipment which enables it to meet the desired operating parameters (Sacilik et al., 2006).

Drying behaviour is described using the following categories of mathematical models: theoretical models, semi-theoretical models, and empirical models (Rodríguez et al., 2014).

Theoretical models are based on the theory of mass and heat transfer laws. They respect the fundamentals of the drying process and their parameters have a physical meaning. Theoretical simulations may provide explanations for various phenomena, which occur during the drying process. However, the models discussed are time consuming because the diffusion equations governing the process are complicated (Kaleta and Górnicki, 2010b). Theoretical

(C) 2020 Institute of Agrophysics, Polish Academy of Sciences 
models have been applied to describe the drying kinetics of such biological materials as apples (Kowalski and Rybicki, 2017), carrots (Mahapatra and Tripathy, 2018; SánchezSáenz et al., 2015), cherry tomato (Bennamoun et al., 2015), green bean (Doymaz et al., 2015; Tekin et al., 2017), hazelnut (Giraudo et al., 2018), peach (Doymaz, 2014), pumpkin (Agrawal and Methekar, 2017; Junqueira et al., 2017), peppermint leaves (Ashtiani et al., 2017), poppy seeds (Stakić and Urošević, 2011), pre-gelatinized potato starch (Jiang et al., 2017), red beets (Kaleta and Górnicki, 2010b), spinach leaves (Doymaz, 2009), and sunflower seeds (Darvishi et al., 2013).

Recently, a research study has modelled drying kinetics using artificial neural networks (Omari et al., 2018; Özdemir et al., 2017; Rodríguez et al., 2014).

The semi-theoretical models are generally deduced from simplified versions of Fick's second law of diffusion (Ashtiani et al., 2017). The empirical models are mainly formulated from the direct relationship between the moisture content and drying time (Ertekin and Firat, 2017). Mathematical equations obtained in this way have parameters, which are fitted based on the experimental results. The mathematical form of empirical models does not require the consideration of the theory of drying, therefore their parameters are without physical meaning (Kaleta et al., 2013). On account of their simplicity, the models discussed are applied to describe the drying characteristics of different products such as apples (Antal et al., 2015; Atalay et al., 2017), blueberries (Yu et al., 2017), carrots (Aghbashlo et al., 2011; Mahapatra and Tripathy, 2018), canola (Gazor and Mohsenimanesh, 2010), cashew (Dhanushkodi et al., 2017), dill leaves (Motevali et al., 2013), garlic (Younis et al., 2018), green bean (Doymaz et al., 2015; Tekin et al., 2017), Hass avocado seeds (Avhad and Marchetti, 2016), kiwi fruit (Tian et al., 2015), Moroccan rosemary leaves (Mghazli et al., 2017), peach (Doymaz, 2014), pumpkin (Junqueira et al., 2017), rice (Hacihafizoğlu et al., 2008), spinach leaves (Doymaz, 2009), sweet basil (Phoungchandang and Kongpim, 2012), tomato (Azeez et al., 2017), Vernonia amygdalina leaves (Alara et al., 2017). Some authors have described the effect of drying variables on the parameters of empirical models, in these cases such models may be considered to be more general. In the literature, the predicted parameter values were correlated as a function of drying air temperature (Alara et al., 2017; Kaleta et al., 2013; Mghazli et al., 2017), drying air temperature and airflow velocity (Hosseinabadi et al., 2012), characteristic particle dimension and initial material load (Kaleta et al., 2013), airflow velocity, drying air temperature, characteristic particle dimension and the initial height of the layer (Kaleta and Górnicki, 2010a), wood species and drying air temperature (Górnicki et al., 2017). No information was obtained concerning the examination of the effect of the vegetables species on the parameters of the drying models. Therefore, the objective of this paper was to investigate the effect of the vegetable species, drying air temperature and slice thickness on the parameters of the drying models.

As mentioned previously, some authors have described the effect of drying variables on the parameters of the empirical models in order to make these models more widely applicable. The effect of the type of the material being dried was only determined for wood (Górnicki et al., 2017). Therefore, the authors investigated the effect of conditions of conducting drying process (air drying temperature, slice thickness) and also the effect of differences in the biological and mechanical structure of vegetables.

\section{MATERIAL AND METHODS}

Onions and roots of carrot, parsley, and red beet were obtained from a local market. The material was washed in water, hand peeled, and cut into slices ( 5 and $10 \mathrm{~mm}$ thickness) with a cutting machine, and then dried on the same day. The initial moisture content varied between 9.29 and $9.72 \mathrm{~kg} \mathrm{H}_{2} \mathrm{O} \mathrm{kg}^{-1}$ d.m. for carrot, 4.77 and $5.24 \mathrm{~kg} \mathrm{H}_{2} \mathrm{O} \mathrm{kg}^{-1}$ d.m. for parsley, 7.55 and $8.00 \mathrm{~kg} \mathrm{H}_{2} \mathrm{O} \mathrm{kg}^{-1}$ d.m. for red beet, 7.10 and $8.80 \mathrm{~kg} \mathrm{H}_{2} \mathrm{O} \mathrm{kg}^{-1} \mathrm{~d}$.m. for onion. The product moisture content was determined according to the standard procedure (Horwitz, 2005).

The experiments were conducted in a laboratory dryer - Memmert UFP400 (MEMMERT GmbH+Co. KG, Schwabach, Germany) - under natural convection conditions. Three drying air temperatures namely, 50, 60, and $70^{\circ} \mathrm{C}$ were used in the experiments. The measurements were performed in the following manner. The sample was uniformly spread as a thin-layer on the tulle stretched on a metal frame (scale) and then hung up on the scales WPX 650 (RADWAG, Radom, Poland). The weighing accuracy was $\pm 1 \mathrm{mg}$. Changes in the sample mass were recorded each $60 \mathrm{~s}$ using a computer connected to the scales. Drying was continued until there was no mass change. The experiments were performed in three repetitions.

The air temperature inside the dryer was measured using thermocouple TP-01b-W3 (CZAKI THERMOPRODUCT, Raszyn, Poland). The thermocouple was placed at the centre of the drying chamber. The temperature was measured with $\pm 0.1^{\circ} \mathrm{C}$ accuracy.

Table 1 shows the empirical models applied to describe the drying characteristics of carrot, parsley, red beetroots and onions ( $a, b, k$, and $n$ are the model parameters). Simple models with only one or two parameters were chosen. These drying models are very often used, especially in practical drying.

The dimensionless moisture ratio $M R$ is calculated using Eq. (1):

$$
\mathrm{MR}=\frac{M_{t}-M_{e}}{M_{0}-M_{e}}
$$

where: $M_{t}$ is the moisture content at $t\left(\mathrm{~kg} \mathrm{H}_{2} \mathrm{O} \mathrm{kg}{ }^{-1}\right.$ d.m. $)$, $t$ is time (s), $M_{e}$ is the equilibrium moisture content $\left(\mathrm{kg} \mathrm{H}_{2} \mathrm{O}\right.$ $\mathrm{kg}^{-1}$ d.m.), and $M_{0}$ is the initial moisture content $\left(\mathrm{kg} \mathrm{H}_{2} \mathrm{O}\right.$ $\mathrm{kg}^{-1}$ d.m.). 
The initial and equilibrium moisture content of the samples were determined gravimetrically by drying in a laboratory oven at a temperature of $105^{\circ} \mathrm{C}$ and atmospheric pressure for a period of $24 \mathrm{~h}$, until completely dry (Lutovska et al., 2017).

The drying curves obtained from the experiments were fitted to the five tested models presented in Table 1. The data were analysed using the computer program Dell Statistica (ver. 13; Dell Inc., Tulsa, OK, USA). A non-linear regression analysis was carried out using the LavenbergMarquardt method and thus the model parameters were determined. When statistical analyses are carried out to identify the best fit, frequently used statistical criteria are the determination coefficient $\left(\mathrm{R}^{2}\right)$, reduced chi-square $\left(\chi^{2}\right)$, the root mean square error (RMSE), and the t-static method (t-stat) (Azeez et al., 2017; Kaleta et al., 2013). The criteria mentioned above may be calculated using Eqs (2)-(5):

$$
\begin{gathered}
\mathrm{R}^{2}=\frac{\sum_{i=1}^{N}\left(\mathrm{MR}_{\mathrm{i}}-\mathrm{MR}_{\mathrm{pre}, \mathrm{i}}\right) \sum_{i=1}^{N}\left(\mathrm{MR}_{i}-\mathrm{MR}_{\mathrm{exp}, i}\right)}{\sqrt{\left[\sum_{i=1}^{N}\left(\mathrm{MR}_{i}-\mathrm{MR}_{\mathrm{pre}, i}\right)^{2}\right]\left[\sum_{i=1}^{N}\left(\mathrm{MR}_{i}-\mathrm{MR}_{\mathrm{ex}, i}\right)^{2}\right]}}, \\
\mathrm{RMSE}=\left[\frac{1}{N} \sum_{i=1}^{N}\left(\mathrm{MR}_{\mathrm{pre}, i}-\mathrm{MR}_{\mathrm{exp}, i}\right)^{2}\right]^{1 / 2}, \\
\chi^{2}=\frac{\sum_{i=1}^{N}\left(\mathrm{MR}_{\mathrm{exp}, i}-\mathrm{MR}_{\mathrm{pre}, i}\right)^{2}}{N-n}, \\
t \text {-stat }=\left[\frac{(n-1) \mathrm{MBE}^{2}}{\mathrm{RMSE}^{2}-\mathrm{MBE}^{2}}\right]^{1 / 2}
\end{gathered}
$$

where: $M R_{\text {exp }}$ and $M R_{\text {pre }}$ are dimensionless moisture ratios obtained from experimental results and modelling, respectively, $N$ is the number of observations, $n$ is the number of parameters in the drying model, $i$ is the number of terms, and $M B E$ (mean bias error) is calculated according to Eq. (6):

$$
\mathrm{MBE}=\frac{1}{N} \sum_{i=1}^{N}\left(\mathrm{MR}_{\mathrm{pre}, i}-\mathrm{MR}_{\exp , i}\right),
$$

where $\mathrm{R}^{2}$ takes the values between 0 and 1 . The closer it is to 1 , the closer the relationship between the experimental and predicted values. The RMSE value is required to reach 0 . Lower RMSE values indicate better fitness of the established model. The lower the values of $\chi^{2}$ and $t$-stat, the better the goodness of the fit.

The effect of the vegetable species (VS), drying air temperature $\left(T,{ }^{\circ} \mathrm{C}\right)$, and slice thickness $(L, \mathrm{~mm})$ on the model parameters were investigated in the following manner. The parameters of the applied models 1-5 involving the considered variables were obtained by taking into account the following equations: summation: $X=\mathrm{f}(\mathrm{VS})+\mathrm{f}(T)+\mathrm{f}(L)$, subtraction $X=\mathrm{f}(\mathrm{VS})-\mathrm{f}(T)-\mathrm{f}(L)$, multiplication $X=\mathrm{f}(\mathrm{VS}) \mathrm{f}(T)$ $\mathrm{f}(L)$, division $X=(\mathrm{f}(\mathrm{VS}) / \mathrm{f}(T)) / \mathrm{f}(L), \quad(X$ is the variable). The influence of $T$ was described by applying several different equations, namely: linear $\mathrm{f}(T)=A+B T$, logarithmic (common) $\mathrm{f}(T)=A+B \log (T)$, rational $\mathrm{f}(T)=A+B T^{-1}$, square $\mathrm{f}(T)=A+B T+C T^{2} . A, B, C$ are coefficients independent of the vegetable species and slice thickness. The influence of $L$ was expressed by accepting the following type of dependencies: linear $\mathrm{f}(L)=D+E L$, logarithmic (common) $\mathrm{f}(L)=D+E \log (L)$, rational $\mathrm{f}(L)=D+E L^{-1}$, and square $\mathrm{f}(L)=D+E L+F L^{2}$. Coefficients $D, E, F$ are independent of the vegetable species and drying air temperature. The influence of VS on the drying model parameters was determined using the $A_{v}$ coefficient (f(VS) $=A_{v}$ ). $A_{v}$ is the coefficient independent of $T$ and $L$ and its value depends only on the type of vegetable.

\section{RESULTS AND DISCUSSION}

The moisture ratio versus time diagram for the drying of the investigated vegetables is presented in Fig. 1. Each of the drying curves $M R(t)$ represents an empirical formula. The empirical formula approximates the results of three measurement repetitions of the moisture ratio changes over time. It may be assumed that the drying process of the slices of the considered vegetables was affected by the vegetable species. Figure 1 shows that the drying time for carrot and red beetroots and onions may be regarded as almost the same. It may be observed that the drying process of parsley root slices is slower than that of other vegetable species, however, the drying time may be considered to be the same. The same trends that were observed for drying at $70^{\circ} \mathrm{C}$ were obtained at 50 and $60^{\circ} \mathrm{C}$, and for slices of $10 \mathrm{~mm}$ thickness.

There is no information in the literature concerning a comparison of the drying curves of carrots, parsley, red beets, and onions although the drying process of these vegetables were investigated (Górnicki and Kaleta, 2007; Planinić et al., 2005; Shynkaryk et al., 2008).

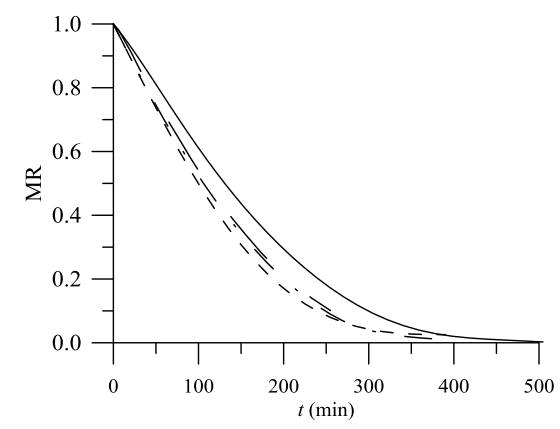

Fig. 1. Moisture ratio versus time for drying the investigated vegetable species slices of $5 \mathrm{~mm}$ thickness at $70^{\circ} \mathrm{C}$ air temperature: $(-)$ parsley, $(--)$ ) onion, $(-\cdot-)$ carrot, (- - -) red beet. 
Table 1. Considered thin-layer models

\begin{tabular}{llll}
\hline Model No. & Model equation & Model name & References \\
\hline 1 & $\operatorname{MR}(t)=\exp (-k t)$ & Lewis (Newton) & (Lewis, 1921) \\
2 & $\operatorname{MR}(t)=a \exp (-k t)$ & Henderson and Pabis & (Henderson and Pabis, 1961) \\
3 & $\operatorname{MR}(t)=\exp \left(-k t^{n}\right)$ & Page & (Page, 1949) \\
4 & $\operatorname{MR}(t)=\exp \left[-(k t)^{n}\right]$ & Modified Page & (Overhults et al., 1973) \\
5 & $\operatorname{MR}(t)=1+a t+b t^{2}$ & Wang and Singh & (Wang and Singh, 1978) \\
\hline
\end{tabular}

Table 2. Results of statistical analyses in describing the drying model parameters using a summation and subtraction equation

\begin{tabular}{|c|c|c|c|c|c|}
\hline Model No. & Parameter & $\mathrm{R}^{2}$ & $R M S E$ & $\chi^{2}$ & $t$-stat \\
\hline 1 & $k$ & $0.9682-0.9703$ & 0.0003 & 0.0000 & $0.0010-0.0486$ \\
\hline \multirow{2}{*}{2} & $k$ & $0.5073-0.6294$ & $0.0012-0.0014$ & 0.0000 & $0.0000-0.0114$ \\
\hline & $a$ & $0.5117-0.6283$ & $0.0158-0.0181$ & $0.0003-0.0004$ & $0.0000-0.0016$ \\
\hline \multirow{2}{*}{3} & $k$ & $0.1999-0.4124$ & 0.0004 & 0.0000 & $0.0000-0.0178$ \\
\hline & $n$ & $0.6481-0.7342$ & $0.0431-0.0500$ & $0.0021-0.0028$ & $0.0000-0.0012$ \\
\hline \multirow{2}{*}{4} & $k$ & $0.9681-0.9752$ & 0.0003 & 0.0000 & $0.0000-0.0127$ \\
\hline & $n$ & $0.6419-0.7342$ & $0.0431-0.0500$ & $0.0021-0.0028$ & $0.0000-0.0019$ \\
\hline \multirow{2}{*}{5} & $a$ & $0.9404-0.9453$ & 0.0003 & 0.0000 & $0.0002-0.0291$ \\
\hline & $b$ & $0.8743-0.8771$ & 0.0000 & 0.0000 & $0.0001-4.8603$ \\
\hline
\end{tabular}

Table 3. Results of statistical analyses concerning the modelling of the drying process of carrot, parsley, red beet and onions (the model parameters are described by summation, subtraction, multiplication and division equations)

\begin{tabular}{ccccc}
\hline Model No. & $\mathrm{R}^{2}$ & $R M S E$ & $\chi^{2}$ & $t$-stat \\
\hline 1 & $0.9604-0.9620$ & $0.0672-0.0682$ & $0.0045-0.0047$ & $1.0704-1.4191$ \\
2 & $0.9503-0.9570$ & $0.0718-0.0768$ & $0.0053-0.0060$ & $4.0153-6.6940$ \\
3 & $0.9690-0.9699$ & $0.0587-0.0600$ & $0.0035-0.0037$ & $0.6739-2.5203$ \\
4 & $0.9688-0.9701$ & $0.0587-0.0600$ & $0.0035-0.0037$ & $2.0100-2.5548$ \\
\hline
\end{tabular}

An evaluation of the empirical models was applied to describe the drying characteristics of carrot, parsley, red beetroots and onions, it was carried out in the following manner. The moisture content data received from the experiments for different $T$ and $L$ values were changed to a dimensionless moisture ratio formula. The next step was the curve fitting computations with the drying time taking into account the models given in Table 1. Then the regressions were taken into account to explain the influence of the vegetable species, air temperature, and slice thickness on the parameters of the models under considerations. The effects of VS, $T$, and $L$ on the model parameters were also included in the models. The following types of dependencies were examined: summation, subtraction, multiplication, and division. Linear, rational, logarithmic (common), and square types of equation were applied for the air drying temperature and slice thickness. The parametes combinations giving the highest values of $\mathrm{R}^{2}$ were then considered in the final model. The dependencies obtained, along with the determined coefficients were then applied to calculate the moisture ratio of carrot, parsley, red beetroots and onions at any time during the drying process. The models developed were validated by comparing the measured and computed moisture ratios in any particular drying course.

Statistical analyses indicated that the parameters of the models determined by summation and subtraction equations (with the linear, logarithmic (common), rational, and square types of equation for the air drying temperature and slice thickness) may be assumed to be appropriate for the five drying models under consideration (Table 2). The $R M S E$ values varied between 0.0000 and 0.0500 , the $\chi^{2}$ values ranged from 0.0000 to 0.0028 , while the $t$-stat values ranged from 0.0000 to 0.0486 (for model 5 from 0.0001 to 4.8603). The values of the determination coefficient $\left(\mathrm{R}^{2}\right)$ are slightly less satisfactory and for models 1, 2, 4, and 5 they varied from between 0.5073 and 0.9752 , however, for model 3, the $\mathrm{R}^{2}$ values ranged from 0.1999 to 0.7342 .

All of the parameter equations discussed above were then substituted into the tested models to predict the course of the drying curves for carrot, parsley, and red beetroos and onios slices of 5 and $10 \mathrm{~mm}$ thickness in the temperature range of $50-70^{\circ} \mathrm{C}$. The results of the statistical analyses are presented in Table 3. The results for the Wang and Singh 
model (model 5) are not inserted into Table 3 because they turned out to be unacceptable. The other tested models, namely: Lewis (Newton) (model 1), Henderson and Pabis (model 2), Page (model 3), and Modified Page (model 4) fitted very well to the experimental data. The determination coefficient values are high enough (0.9503-0.9701), RMSE varied between 0.0587 and $0.0768, \chi^{2}$ ranged from 0.0035 to 0.0060 , and the $t$-stat value varied from 0.6739 to 6.6940 .

The effect of VS, $T$, and $L$ on the model parameters may be taken into consideration on an individual basis (Table 4). The coefficients of the chosen parameter equations for carrot, parsley, red beetroos and onios drying models are shown in Table 4 . The $A_{v}$ parameter has different values for different vegetables, which indicates the effect of the type of vegetable ( $A_{v}$ depends on the vegetable species) on the kinetics of the drying process (Fig. 1). By substituting these coefficients into parameter equations and then considering the aforementioned formulas in the examined models, the course of the drying curve of the considered vegetables may be predicted. The parameter equations given in Table 4 are those, which were substituted into an adequate drying model to allow for the most precise description of the drying curves. The results of statistical analyses for the examined descriptions are presented in Table 4. It may be stated that the following models: Lewis (Newton) (model 1), Henderson and Pabis (model 2), Page (model 3), and Modified Page (model 4) with parameter equations adequate for each considered model given in Table 4 fitted very well to the experimental data. Figure 2 confirms the existence of an acceptable correlation between the experimental and predicted moisture ratios (for all considered vegetables) and shows that the considered models are appropriate for predicting the drying characteristics of carrot, parsley, red beetroots and onions.

To summarize, the drying models given in Table 4 may be used to describe the drying kinetics of carrot, parsley, red beetroos and onios slices of 5 and $10 \mathrm{~mm}$ thickness in the temperature range of $50-70^{\circ} \mathrm{C}$. The Page model with parameters evaluated using a summation equation and square type dependence for drying air temperature and a rational one for slice thickness may be considered, however, as the most satisfactory model $\left(\mathrm{R}^{2}=0.9699, R M S E=0.0587\right.$, $\chi^{2}=0.0035, t$-stat $=0.6739$ ). The statistical analyses results describing the Page model parameters using the dependencies mentioned above are the following: $R^{2}=0.4017$, $R M S E=0.0004, \chi^{2}=0.0000, t$-stat $=0.0126$ for $k$ and $\mathrm{R}^{2}=$ $0.7194, R M S E=0.0442, \chi^{2}=0.0022, t$-stat $=0.0004$ for $n$.

The investigations revealed that there is a possibility of generalizing the empirical models considered. The inclusion of the appropriate VS material coefficient into the parameters of these models gives the chance of predicting the drying process of various vegetables with a significantly high degree of accuracy. 

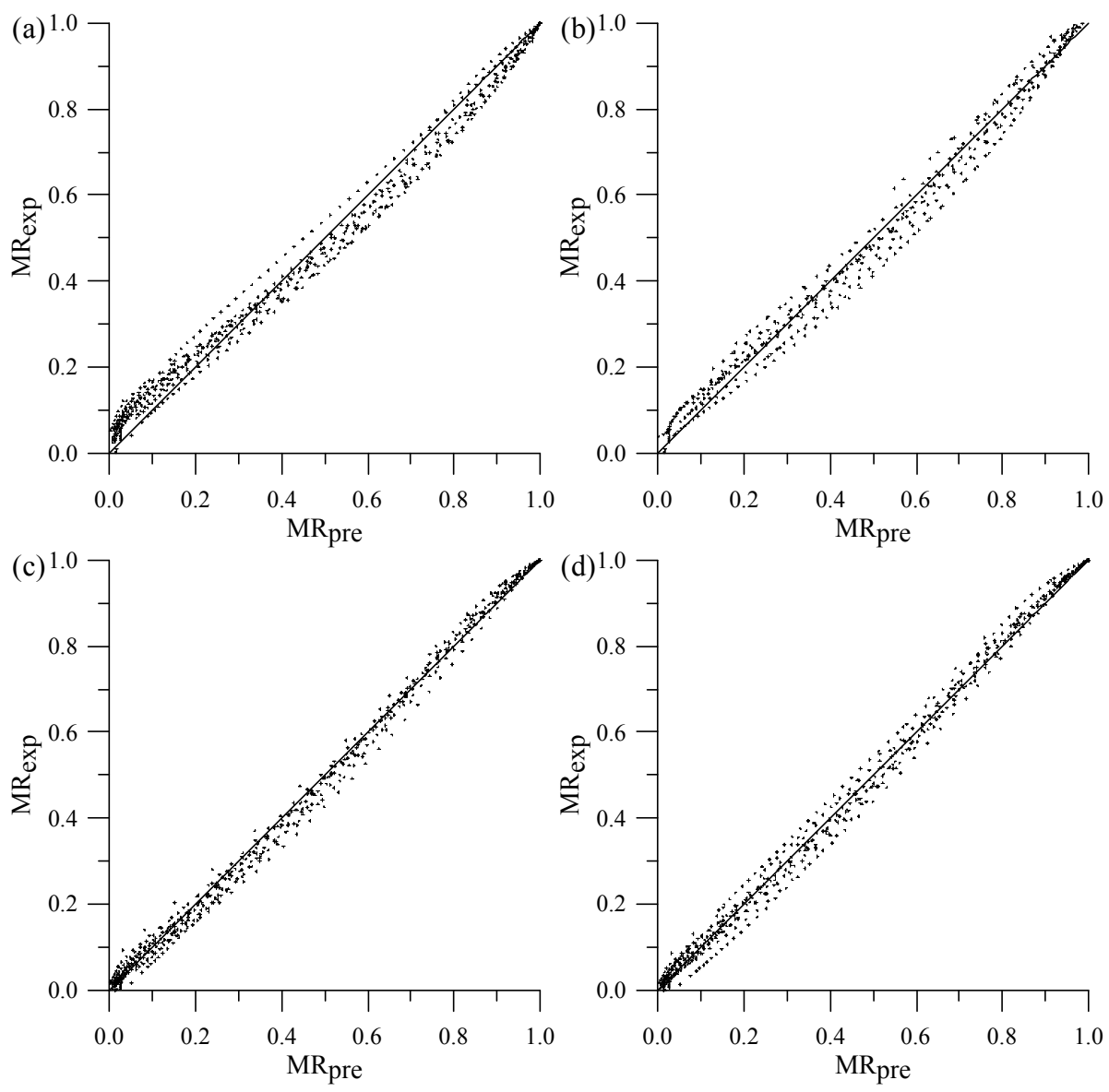

Fig. 2. Comparison of experimental and predicted moisture ratios by: (a) Lewis (Newton) model, (b) Henderson and Pabis model, (c) Page model, (d) Modified Page model (all of the discussed models have an appropriate parameter equation from Table 4).

\section{CONCLUSIONS}

1. It appears that the effect of vegetable species, drying air temperature, and slice thickness on the model (Lewis (Newton), Henderson and Pabis, Page, Modified Page, Wang and Singh) parameters can be taken into account individually.

2. All models, except that developed by Wang and Singh, with the parameters calculated considering the effect of temperature, slice thickness, and vegetable species may be applied to describe the drying kinetics of carrot, parsley, and red beetroos and onios slices of 5 and $10 \mathrm{~mm}$ thickness in the temperature range of $50-70^{\circ} \mathrm{C}$.

3. The Page model with the parameters evaluated using a summation equation and square type dependence for drying air temperature and a rational one for slice thickness may be considered to be the most adequate $\left(\mathrm{R}^{2}=0.9699\right.$, $R M S E=0.0587, \chi^{2}=0.0035, t$-stat $\left.=0.6739\right)$.

Conflict of interest: The authors declare that they have no conflict of interest.

Compliance with Ethical Requirements: This study does not contain any experiment involving human or animal subjects.

\section{REFERENCES}

Aghbashlo M., Kianmehr M.H., Arabhosseini A., and Nazghelichi T., 2011. Modelling the carrot thin-layer drying in a semi-industrial continuous band dryer. Czech J. Food Sci., 29(5), 528-538. https://doi.org/10.17221/158/2010-cjfs

Agrawal S.G. and Methekar R.N., 2017. Mathematical model for heat and mass transfer during convective drying of pumpkin. Food Bioprod. Process., 101, 68-73. https://doi.org/10.1016/j.fbp.2016.10.005

Alara O.R., Abdurahman N.H., and Olalere O.A., 2017. Mathematical modelling and morphological properties of thin layer oven drying of Vernonia amygdalina leaves. J. Saudi Soc. Agric. Sci., 18(3), 309-315. https://doi.org/10.1016/j.jssas.2017.09.003

Antal T., Kerekes B., Sikolya L., and Tarek M., 2015. Quality and drying characteristics of apple cubes subjected to combined drying (FD pre-drying and HAD finish-drying): Apple drying. J. Food Process. Preserv., 39(6), 994-1005. https://doi.org/10.1111/jfpp.12313

Ashtiani S.-H.M., Salarikia A., and Golzarian M.R., 2017. Analyzing drying characteristics and modeling of thin layers of peppermint leaves under hot-air and infrared treatments. Inf. Process. Agric., 4(2), 128-139. https://doi.org/10.1016/j.inpa.2017.03.001 
Atalay H., Çoban M.T., and Kıncay O., 2017. Modeling of the drying process of apple slices: Application with a solar dryer and the thermal energy storage system. Energy, 134, 382-391. https://doi.org/10.1016/j.energy.2017.06.030

Avhad M.R. and Marchetti J.M., 2016. Mathematical modelling of the drying kinetics of Hass avocado seeds. Ind. Crops Prod., 91, 76-87. https://doi.org/10.1016/j.indcrop.2016.06.035

Azeez L., Adebisi S.A., Oyedeji A.O., Adetoro R.O., and Tijani K.O., 2017. Bioactive compounds' contents, drying kinetics and mathematical modelling of tomato slices influenced by drying temperatures and time. J. Saudi Soc. Agric. Sci., 18(2), 120-126. https://doi.org/10.1016/j.jssas.2017.03.002

Barba A.A., d'Amore M., Rispoli M., Marra F., and Lamberti G., 2014. Microwave assisted drying of banana: Effects on reducing sugars and polyphenols contents. Czech J. Food Sci., 32(4), 369-375. https://doi.org/10.17221/536/2013-cjfs

Bennamoun L., Khama R., and Léonard A., 2015. Convective drying of a single cherry tomato: Modeling and experimental study. Food Bioprod. Process., 94, 114-123. https://doi.org/10.1016/j.fbp.2015.02.006

Darvishi H., Hadi Khoshtaghaza M., Najafi G., and Zarein M., 2013. Characteristics of sunflower seed drying and microwave energy consumption. Int. Agrophys., 27(2), 127-132. https://doi.org/10.2478/v10247-012-0077-8

Dhanushkodi S., Wilson V.H., and Sudhakar K., 2017. Mathematical modeling of drying behavior of cashew in a solar biomass hybrid dryer. Resour.-Effic. Technol., 3(4), 359364. https://doi.org/10.1016/j.reffit.2016.12.002

Doymaz I., 2009. Thin-layer drying of spinach leaves in a convective dryer. J. Food Process Eng., 32(1), 112-125. https://doi.org/10.1111/j.1745-4530.2007.00205.x

Doymaz I., 2014. Suitability of thin-layer drying models for infrared drying of peach slices: Infrared Drying of Peach Slices. J. Food Process. Preserv., 38(6), 2232-2239. https://doi.org/10.1111/jfpp.12277

Doymaz I., Kipcak A.S., and Piskin S., 2015. Characteristics of thin-layer infrared drying of green bean. Czech J. Food Sci., 33(1), 83-90. https://doi.org/10.17221/423/2014-cjfs

Ertekin C. and Firat M.Z., 2017. A comprehensive review of thin-layer drying models used in agricultural products. Crit. Rev. Food Sci. Nutr., 57(4), 701-717.

Gazor H.R. and Mohsenimanesh A., 2010. Modelling the drying kinetics of canola in fluidised bed dryer. Czech J. Food Sci., 38(6), 531-537. https://doi.org/10.17221/256/2009-cjfs

Giraudo A., Valentini N., Venturello A., Savorani F., Bertone E., Bonazzola G., Zeppa G., and Geobaldo F., 2018. Kinetic modeling of hazelnut drying: Effects of different cultivars and drying parameters. J. Food Process Eng., 41(1), e12632. https://doi.org/10.1111/jfpe.12632

Górnicki K. and Kaleta A., 2007. Modelling convection drying of blanched parsley root slices. Biosyst. Eng., 97(1), 51-59. https://doi.org/10.1016/j.biosystemseng.2007.02.006

Górnicki K., Kaleta A., Bryś A., and Winiczenko R., 2017. Modelling of drying curves of spruce, beech, willow and alder particles. Drv. Ind., 68(1), 11-16. https://doi.org/10.5552/drind.2017.1602

Hacıhafızoğlu O., Cihan A., and Kahveci K., 2008. Mathematical modelling of drying of thin layer rough rice. Food Bioprod. Process., 86(4), 268-275. https://doi.org/10.1016/j.fbp.2008.01.002
Henderson S.M. and Pabis S., 1961. Grain drying theory. I. Temperature effect on drying coefficient. J. Agric. Eng. Res., 6, 169-174.

Horwitz W. (Ed.), 2005. Official methods of analysis of AOAC International. AOAC Int.: Gaithersburg, MD, USA.

Hosseinabadi H.Z., Doosthoseini K., and Layeghi M., 2012. Drying kinetics of poplar (Populus Deltoides) wood particles by a convective thin layer dryer. Drv. Ind., 63(3), 169-176. https://doi.org/10.5552/drind.2012.1201

Jiang J., Dang L., Yuensin C., Tan H., Pan B., and Wei H., 2017. Simulation of microwave thin layer drying process by new theoretical model. Chem. Eng. Sci., 162, 69-76. https://doi.org/10.1016/j.ces.2016.12.040

Junqueira J.R. de J., Corrêa J.L.G., and Ernesto D.B., 2017. Microwave, convective, and intermittent microwave-convective drying of pulsed vacuum osmodehydrated pumpkin slices. J. Food Process. Preserv., 41(6), e13250.

https://doi.org/10.1111/jfpp. 13250

Kaleta A. and Górnicki K., 2010a. Evaluation of drying models of apple (var. McIntosh) dried in a convective dryer. Int. J. Food Sci. Technol., 45(5), 891-898.

https://doi.org/10.1111/j.1365-2621.2010.02230.x

Kaleta A. and Górnicki K., 2010b. Some remarks on evaluation of drying models of red beet particles. Energy Convers. Manag., 51(12), 2967-2978.

https://doi.org/10.1016/j.enconman.2010.06.040

Kaleta A., Górnicki K., Winiczenko R., and Chojnacka A., 2013. Evaluation of drying models of apple (var. Ligol) dried in a fluidized bed dryer. Energy Convers. Manag., 67, 179-185. https://doi.org/10.1016/j.enconman.2012.11.011

Kowalski S.J. and Rybicki A., 2017. Ultrasound in wet biological materials subjected to drying. J. Food Eng., 212, 271-282. https://doi.org/10.1016/j.jfoodeng.2017.05.032

Lewis W.K., 1921. The rate of drying of solid materials. Ind. Eng. Chem., 13(5), 427-432.

Lutovska M., Mitrevski V., Pavkov I., Babic M., Mijakovski V., Geramitcioski T., and Stamenkovic Z., 2017. Different methods of equilibrium moisture content determination. J. Process. Energy Agric., 21(2), 91-96. https://doi.org/10.5937/jpea17020911

Mahapatra A. and Tripathy P.P., 2018. Modeling and simulation of moisture transfer during solar drying of carrot slices. J. Food Process Eng., 41(8), e12909. https://doi.org/10.1111/jfpe.12909

Mghazli S., Ouhammou M., Hidar N., Lahnine L., Idlimam A., and Mahrouz M., 2017. Drying characteristics and kinetics solar drying of Moroccan rosemary leaves. Renew. Energy, 108, 303-310. https://doi.org/10.1016/j.renene.2017.02.022

Motevali A., Younji S., Chayjan R.A., Aghilinategh N., and Banakar A., 2013. Drying kinetics of dill leaves in a convective dryer. Int. Agrophys., 27(1), 39-47. https://doi.org/10.2478/v10247-012-0066-y

Omari A., Behroozi-Khazaei N., and Sharifian F., 2018. Drying kinetic and artificial neural network modeling of mushroom drying process in microwave-hot air dryer. J. Food Process Eng., 41(7), e12849. https://doi.org/10.1111/jfpe.12849

Opalić M., Domitran Z., Komes D., Belščak A., Horžić D., and Karlović D., 2009. The effect of ultrasound pre-treatment and air-drying on the quality of dried apples. Czech J. Food Sci., 27(Special Issue 1), S297-S300. https://doi.org/10.17221/606-cjfs 
Overhults D.G., White G.M., Hamilton H.E., and Ross I.J., 1973. Drying soybeans with heated air. Trans. ASAE, 16(1), 0112-0113. https://doi.org/10.13031/2013.37459

Özdemir M.B., Aktaş M., Şevik S., and Khanlari A., 2017. Modeling of a convective-infrared kiwifruit drying process. Int. J. Hydrog. Energy, 42(28), 18005-18013. https://doi.org/10.1016/j.ijhydene.2017.01.012

Page G.E., 1949. Factors influencing the maximum rates of air drying shelled corn in thin layers. MSc. Thesis, Purdue University, ProQuest Dissertations Publ., West Lafayette, IN, USA.

Phoungchandang S. and Kongpim P., 2012. Modeling using a new thin-layer drying model and drying characteristics of sweet basil (Ocimum baslicum Linn.) using tray and heat pump-assisted dehumidified drying: drying characteristics. J. Food Process Eng., 35(6), 851-862. https://doi.org/10.1111/j.1745-4530.2010.00633.x

Planinić M., Velić D., Tomas S., Bilić M., and Bucić A., 2005. Modelling of drying and rehydration of carrots using Peleg's model. Eur. Food Res. Technol., 221(3-4), 446-451. https://doi.org/10.1007/s00217-005-1200-x

Rodríguez J., Clemente G., Sanjuán N., and Bon J., 2014. Modelling drying kinetics of thyme (Thymus vulgaris L.): Theoretical and empirical models, and neural networks. Food Sci. Technol. Int., 20(1), 13-22. https://doi.org/10.1177/1082013212469614

Sacilik K., Keskin R., and Elicin A.K., 2006. Mathematical modelling of solar tunnel drying of thin layer organic tomato. J. Food Eng., 73(3), 231-238. https://doi.org/10.1016/j.jfoodeng.2005.01.025

Sánchez-Sáenz C.M., de Oliveira R.A., and Park K.J., 2015. HTST Pre-drying influence on vacuum drying kinetics and carrot slices quality parameters evaluation: Vacuum drying kinetics for carrot slices. J. Food Process. Preserv., 39(6), 1636-1646. https://doi.org/10.1111/jfpp.12393

Shynkaryk M.V., Lebovka N.I., and Vorobiev E., 2008. Pulsed electric fields and temperature effects on drying and rehydration of red beetroots. Dry. Technol., 26(6), 695-704. https://doi.org/10.1080/07373930802046260

Stakić M. and Urošević T., 2011. Experimental study and simulation of vibrated fluidized bed drying. Chem. Eng. Process. Process Intensif., 50(4), 428-437. https://doi.org/10.1016/j.cep.2011.02.006

Tekin Z.H., Başlar M., Karasu S., and Kilicli M., 2017. Dehydration of green beans using ultrasound-assisted vacuum drying as a novel technique: drying kinetics and quality parameters. J. Food Process. Preserv., 41(6), e13227. https://doi.org/10.1111/jfpp.13227

Tian Y., Wu S., Zhao Y., Zhang Q., Huang J., and Zheng B., 2015. Drying characteristics and processing parameters for microwave-vacuum drying of kiwifruit (Actinidia deliciosa) slices: Microwave-vacuum drying of kiwifruit slices. J. Food Process. Preserv., 39(6), 2620-2629. https://doi.org/10.1111/jfpp.12512

Wang G.V. and Singh R.P., 1978. A single layer drying equation for rough rice. In: Paper - American Society of Agricultural Engineers. ASAE, St Joseph, MI, USA.

Younis M., Abdelkarim D., and El-Abdein A.Z., 2018. Kinetics and mathematical modeling of infrared thin-layer drying of garlic slices. Saudi J. Biol. Sci., 25(2), 332-338. https://doi.org/10.1016/j.sjbs.2017.06.011

Yu Y., Jin T.Z., and Xiao G., 2017. Effects of pulsed electric fields pretreatment and drying method on drying characteristics and nutritive quality of blueberries. J. Food Process. Preserv., 41(6), e13303. https://doi.org/10.1111/jfpp.13303 